\title{
A efetividade da obrigatoriedade da inserção do critério de sustentabilidade nas compras públicas de 2010 a 2014*
}

\author{
Inclusion effectiveness of sustainability \\ criteria mandatory in public bids from \\ 2010 to 2014
}

Ivo Teixeira Gico J ${ }^{1}$ Lauren Lautenschlager ${ }^{2}$
Recebido em: 28/09/2015. Aprovado em: 24/03/2016.

1 Doutor em Direito pela USP. Doutor em Economia pela UnB. Mestre com Honra Máxima (James Kent Scholar) pela Columbia Law School.

2 Doutoranda em Direito no Centro Universitário de Brasília.

\section{Resumo}

$\mathrm{O}$ artigo tem por objetivo analisar a efetividade da obrigatoriedade na inserção de critérios de sustentabilidade na Administração Pública Federal durante o período de 2010 a 2014. Justifica-se o estudo em face da alteração da Lei de Licitações nº 8.666/93 feita através da Lei n ${ }^{\circ}$ 12.349/10 que deu à licitação mais uma finalidade: a promoção do desenvolvimento nacional sustentável. Foi realizada uma pesquisa empírica com a análise de dados fornecidos pelo MPOG com a verificação de procedimentos licitatórios. Com base nos dados, constatou-se que a Administração Pública Federal nem sempre exige critérios sustentáveis nas compras realizadas, embora esta obrigação esteja prevista em lei, e quando assim faz, referem-se na sua maioria, apenas a vertente ambiental da sustentabilidade. Esses critérios tornam-se mais visíveis nos editais para aquisição de bens e sua exigência não abrange sempre todos os produtos a serem licitados. As licitações sustentáveis que antes ocorriam de forma esparsa e voluntária, hoje se tornaram gerais e obrigatórias.

Palavras-chave: Critérios. Sustentabilidade. Compras públicas.

\begin{abstract}
This article analyze the effectiveness of inclusion sustainability criteria mandatory in Federal Public bids during the period 2010-2014. The study has been justified because Law $\mathrm{n}^{\circ} 12.349 / 10$ that has changed Bidding Law $\mathrm{n}^{\circ}$ 8.666/93 and has given another purpose to the bidding: promotion of national sustainable development. An empirical research has been done with data provided by MPOG checking bidding procedures and it found that the Federal Public Administration does not always require sustainable criteria in its bids and if so does, refer mostly just the environmental aspect of sustainability. These criteria become more visible on bidding documents for acquisition of goods and its requirement not always cover all products to be procured. Sustainable bids that before happened sparse and voluntarily form, now, have become general and compulsory.
\end{abstract}

Keywords: Criteria. Sustainability. Public bids. 


\section{Introdução}

O presente artigo se justifica pela alteração da Lei de Licitações no 8.666/93 feita através da Lei no 12.349/10 que deu à licitação mais uma finalidade: a promoção do desenvolvimento nacional sustentável. O governo brasileiro gasta mais de 600 bilhões de reais por ano com a aquisição de bens e contratações de serviços (15\% do PIB). Em face disto, entendeu-se necessário direcionar o poder de compra do setor público para que tais aquisições ocorressem de forma sustentável ${ }^{3}$.

Assim, além de critérios isonômicos que viabilizem a busca pela proposta mais vantajosa para a Administração, estabeleceram-se critérios sustentáveis para a compra de bens e contratações de serviços ou obras públicas a fim de, por um lado gerar benefícios socioambientais e, por outro, reduzir os impactos ambientais. A redução de tais impactos leva a redução de impactos sobre a saúde humana e aos direitos humanos, além é claro, de induzir e promover o mercado de bens e serviços sustentáveis.

A preocupação com o desenvolvimento sustentável decorre da necessidade de dar ao desenvolvimento um novo viés: a sustentabilidade. É este um novo tipo de desenvolvimento capaz de manter o progresso humano, pois ele atende às necessidades do presente sem comprometer a capacidade de as gerações futuras atenderem a suas próprias necessidades ${ }^{4}$. Na sua essência, o desenvolvimento sustentável é um processo de mudança no qual a exploração dos recursos, o direcionamento dos investimentos, a orientação do desenvolvimento tecnológico e a mudança institucional estão em harmonia e reforçam $\mathrm{o}$ atual e futuro potencial para satisfazer as aspirações e necessidades humanas. Este princípio, reconhecido também internamente ${ }^{5}$, visa o equilíbrio entre proteção am-

Tal preocupação não é exclusiva do governo brasileiro. A norma que regula as contratações públicas nos Estados Unidos (FEDERAL ACQUISITION REGULATION) prevê na parte no 23 PART 23- ENVIRONMENT, ENERGY AND WATER EFFICIENCY, RENEWABLE ENERGY TECHNOLOGIES, OCCUPATIONAL SAFETY, AND DRUG-FREE WORKPLACE.

4 Segundo o Relatório de Burtlant de 1987, denominado Nosso Futuro Comum.

5 Já, em âmbito interno, através da ADI n 3.540-MC, a cúpula do poder judiciário brasileiro assegurou o princípio do desenvolvimento sustentável como fator de obtenção do justo equilíbrio entre as exigências da economia e as da ecologia. Além disso, este tema já foi abordado, por exemplo, na Conferência das Nações Unidas sobre o Meio Am- biental e desenvolvimento econômico de modo que um não acarrete a anulação do outro ${ }^{6}$, devendo servir de norteador das políticas de governo ${ }^{7}$. Porém fazer com que a tríplice vertente da sustentabilidade seja atendida, ainda parece uma meta a ser alcançada.

O objetivo do presente artigo é duplo: analisar se está ocorrendo à inclusão dos critérios sustentáveis nos instrumentos convocatórios realizados pela Administração Pública Federal e, se as mudanças legais e administrativas ocorridas geraram incentivos para a contratação de produtos sustentáveis. Parte-se da hipótese que a Administração Pública Federal está inserindo critérios de sustentabilidade já que a lei assim exige e que as mudanças proporcionaram tal incentivo.

Para tanto, este estudo além desta e das considerações finais, foi dividido em quatro partes, onde na primeira haverá a definição do que se entende por critério de sustentabilidade; na segunda será verificada a sua obrigatoriedade; na terceira será realizada a pesquisa de campo com a metodologia, apresentação e análise dos dados e por fim, na última será abordado sobre o fornecimento de bens e serviços sustentáveis.

\section{Do critério de sustentabilidade}

Através das licitações, determinou-se que o Estado como consumidor, deve promover o desenvolvimento nacional sustentável. De acordo com a doutrina, para que ocorra este tipo de desenvolvimento, é necessário a integração de diversos fatores/sustentabilidades: ambiental (preservação dos recursos naturais), econômico (eficiência da utilização dos recursos e no crescimento quantitativo) e social (redução da pobreza ${ }^{8}$ e a busca pela equidade social).

biente e Desenvolvimento de 1992, na Política Nacional do Meio Ambiente (Lei no 6.938/81) e na própria Constituição da República Federativa do Brasil de 1988, a Declaração de Joanesburgo sobre Desenvolvimento Sustentável de 2002 e a Política Nacional sobre Mudança do Clima (Lei $\left.\mathrm{n}^{\circ} 12.187 / 2009\right)$.

6 Segundo FIORILLO, Celso Pacheco. Curso de direito ambiental brasileiro. 14. ed. São Paulo: Saraiva, 2013.

7 De acordo com AKAOUI, Fernando R. Vidal. Direito ambiental. In: NUNES JÚNIOR, Vidal Serrano. (Coord.). Manual de direitos difusos. São Paulo: Verbatiim, 2009. p. 9 - 83.

8 A eliminação da pobreza, por exemplo, já foi abordada por ROSSETTI, José Paschoal. Introdução à economia. 18. ed. São Paulo: Atlas, 2000; BAER, Werner. A economia brasileira. 2. ed. São Paulo: Nobel, 2002 e MACHADO, Paulo Affonso Leme. Direito ambiental brasileiro. 14. ed. 
Ampliando a gama, podem ser incluído os fatores espacial e cultural, territorial e político 9 . O legislador definiu assim, que as diretrizes de sustentabilidade são, dentre outras:

[...] I - menor impacto sobre recursos naturais como flora, fauna, ar, solo e água; II - preferência para materiais, tecnologias e matérias-primas de origem local; III - maior eficiência na utilização de recursos naturais como água e energia; IV - maior geração de empregos, preferencialmente com mão de obra local; V - maior vida útil e menor custo de manutenção do bem e da obra; VI - uso de inovações que reduzam a pressão sobre recursos naturais; e VII - origem ambientalmente regular dos recursos naturais utilizados nos bens, serviços e obras ${ }^{10}$.

Percebe-se que a escolha de critérios levou em consideração a tríplice dimensão da sustentabilidade: econômica: II - preferência para materiais, tecnologias e matérias-primas de origem local; VI - uso de inovações que reduzam a pressão sobre recursos naturais (tecnologias limpas); ambientais: I - menor impacto sobre recursos naturais como flora, fauna, ar, solo e água, III - maior eficiência na utilização de recursos naturais como água e energia, $\mathrm{V}$ - maior vida útil e menor custo de manutenção do bem e da obra, VII - origem ambientalmente regular dos recursos naturais utilizados nos bens, serviços e obras ${ }^{11}$. Isso não significa que um critério seja exclusivo de uma única vertente (econômica, ambiental e social), já que a relação entre eles é interdependente.

Não se discute aqui os motivos pelos quais a opção legislativa tenha sido esta, nem mesmo se tais critérios levariam a uma sustentabilidade. Isso será abordado em um

São Paulo: Malheiros, 2006.

9 Esta amplitude foi mencionada por SACHS, Ignacy. Desenvolvimento: includente, sustentável, sustentado. Rio de Janeiro: Garamond, 2004.

10 BRASIL. Decreto $n^{\circ} 7.746$, de 5 de Junho de 2012. Regulamenta o art. $3^{\circ}$ da Lei $n^{\circ} 8.666$, de 21 de junho de 1993, para estabelecer critérios, práticas e diretrizes para a promoção do desenvolvimento nacional sustentável nas contratações realizadas pela administração pública federal, e institui a Comissão Interministerial de Sustentabilidade na Administração Pública - CISAP. Disponível em: <http://www. planalto.gov.br/CCIVIL_03/_Ato2011-2014/2012/Decreto/D7746.htm>. Acesso em: 20 jun. 2015, art. $4^{\circ}$ grifos nosso.

$11 \quad$ BRASIL. Decreto $n^{\circ} 7.746$, de 5 de Junho de 2012. Regulamenta o art. $3^{\circ}$ da Lei $n^{\circ} 8.666$, de 21 de junho de 1993, para estabelecer critérios, práticas e diretrizes para a promoção do desenvolvimento nacional sustentável nas contratações realizadas pela administração pública federal, e institui a Comissão Interministerial de Sustentabilidade na Administração Pública - CISAP. Disponível em: <http://www.planalto. gov.br/CCIVIL_03/_Ato2011-2014/2012/Decreto/D7746. htm>. Acesso em: 20 jun. 2015, art. $4^{\circ}$ grifos nosso. outro estudo. Neste ponto, busca-se analisar, uma vez impostos tais critérios, se estes vem sendo inseridos na aquisição de compras realizada pela Administração Pública.

O preço nominalmente mais baixo nem sempre é o menor preço, já que devem ser considerados outros fatores como, por exemplo, o rendimento de tal bem ${ }^{12}$. Quando se trata, por exemplo, de um produto sustentável, além do preço, os custos ao longo de toda a sua vida útil também devem ser considerados (preço de compra, custos de utilização e manutenção, custos de eliminação). Assim, é necessária uma releitura do que entende por "melhor preço". Nesse sentido, o procedimento licitatório nem sempre será eficaz quando a qualidade do bem ou produto estiver em jogo, sendo viável apenas quando o preço do bem ou serviço a ser comprado for a única preocupação do comprador ${ }^{13}$.

\section{Obrigatoriedade}

A obrigação de licitar encontra-se prevista no art. 37, XXI, da Constituição da República Federativa do Brasil de 1988. Tal dispositivo foi regulamentado pela Lei n. ${ }^{\circ}$ 8.666/93 e suas alterações.

O procedimento licitatório possui uma gama de princípios próprios ${ }^{14}$ e desenvolve-se através de uma sucessão de atos vinculados devendo propiciar igual oportunidade aos interessados e buscando atuar como fator de eficiência e moralidade nos negócios administrativos ${ }^{15}$.

Os objetivos deste procedimento podem ser assim definidos:

12 Conforme MELLO, Celso Antônio Bandeira de. Curso de direito administrativo. 29. ed. São Paulo: Malheiros, 2012.

13 Conforme o original, CROCKER, Keith J.; MASTEN, Scott E. Regulation and administered contracts revisited: lessons from transaction-cost economics for public utility regulation. Journal of Regulatory Economics. Dordrecht: Kluwer Academic Publishers, 1996, v. 9, p. 5-39. Disponível em: <http://deepblue.lib.umich.edu/bitstream/ handle/2027.42/47841/11149_2004_Article_BF00134817. pdf? sequence $=1$ \&isAllowed $=y>$. Acesso em: 02 fev. 2015. [...] while competitive bidding can be an effective way of determining the lowest cost supplier where the price of the good or service being procured is the buyer's only concern, competitive bidding works less well for complex goods and services where the buyer cares about quality, reliability, and other attributes of the procurement.

14 Dentre eles: princípio da legalidade, princípio da isonomia, princípio da probidade administrativa, princípio da vinculação ao instrumento convocatório, princípio do julgamento objetivo, princípio do interesse público e princípio da economicidade.

15 MEIRELLES, Hely Lopes. Direito administrativo brasileiro. 35. ed. São Paulo: Malheiros, 2009. 
O mecanismo de concurso público é utilizado para servir três objetivos: (1) para garantir a integridade na adjudicação de contratos e para evitar contratação contaminado com favoritismo, conflito de interesses, ou corrupção; (2) para permitir que o governo estabeleça uma contratação economicamente eficiente; e (3) para proporcionar uma oportunidade igual a todos os membros da sociedade para competir ${ }^{16}$.

Poder-se-ia dar uma interpretação sistemática e teológica aos artigos 3o 170 e 225 da Constituição da República Federativa Brasileira de 1988, a fim de identificar a preocupação com a forma de desenvolvimento que o Brasil deve adotar. Porém, por ser esta atividade hermenêutica restrita, o governo brasileiro optou por disciplinar sobre a inserção de critérios sustentáveis.

Antes disso, houveram ainda algumas tentativas de conciliar as compras públicas e a preservação ambiental através de algumas normas federais ${ }^{17}$ e estaduais ${ }^{18}$, além de alguns programas esparsos, como o Programa de Eficiência do Gasto Público - PEG ${ }^{19}$; o Programa Nacional de Conservação de Energia Elétrica (PROCEL) ${ }^{20}$; a Agenda Ambiental na Administração Pública - A3P ${ }^{21}$; a Coleta Seletiva Solidária ${ }^{22}$ e o Projeto Esplanada Sustentável (PES) ${ }^{23}$, antes da mudança legal ocorrida.

16 Conforme o original, DEKEL, Omer. The legal theory of competitive bidding for government contracts. Public Contract Law Journal, v. 37, n. 2, p. 237-268, 2008. Disponível em: <http://www.jstor.org/discover/10.2307/25755452?sid $=21105412419281 \&$ uid $=60 \&$ ruid $=2134 \&$ uid $=3737664 \&$ uid $=2$ \&uid $=2484585797$ \&uid $=2484585807$ \&uid $=3$ \&uid $=70>$. Acesso em: 10 dez. 2014 [...] the public tender mechanism is meant to serve three objectives: (1) to ensure integrity in the awarding of contracts and to prevent contracting tainted with favoritism, conflicts of interest, or corruption; (2) to allow Government to engage in economically efficient contracting; and (3) to provide an equal opportunity to all members of society to compete for the economic advantage inherent in contracting with the Government.

17 Vide por exemplo, o Decreto n ${ }^{\circ} 2.783 / 98$ e a Política Nacional de Resíduos Sólidos (Lei n 12.305/2010).

18 Possuem referências de acordo com o site do Ministério do Meio Ambiente (MMA) os Estados de São Paulo, Mato Grosso, Rio de Janeiro, Espírito Santo e Distrito Federal.

19 Desenvolvido no âmbito da Secretaria de Orçamento Federal do Ministério do Planejamento, Orçamento e Gestão - SOF/MP.

20 Coordenado pela Secretaria de Planejamento e Desenvolvimento Energético do Ministério de Minas e Energia SPE/MME.

21 Coordenado pela Secretaria de Articulação Institucional e Cidadania Ambiental do Ministério do Meio Ambiente SAIC/MMA.

22 Desenvolvida no âmbito da Secretaria-Executiva do Ministério do Desenvolvimento Social e Combate à Fome - SE/MDS.

23 Coordenado pelo Ministério do Planejamento, Orçamento e Gestão, por meio da SOF/MP, em articulação com o MMA, MME e MDS.
A exigência em lei de critérios de sustentabilidade para as compras públicas foi impulsionada pela Instrução Normativa $n^{\circ}$ 01/2010 da Secretaria de Logística e Tecnologia da Informação do Ministério do Planejamento, Orçamento e Gestão - IN nº 01/2010 SLTI-MPOG e pela da Medida Provisória no 495/2010 que foi convertida na Lei ${ }^{\circ}$ 12.349/2010.

A alteração na Lei de Licitações uniu dois objetivos diferentes que existiam dentro do Poder Executivo: os encaminhadores ${ }^{24}$ da Medida provisória buscavam a promoção do desenvolvimento puramente econômico ${ }^{25}$ (já que no $₫ 5^{\circ}$ do art. $3^{\circ}$ foi estabelecida uma margem de preferência para produtos manufaturados e serviços nacionais aos processos de licitação) e, a Secretaria de Logística e Tecnologia da Informação do Ministério do Planejamento buscava a promoção do desenvolvimento sustentável (fixando critérios de sustentabilidade às compras públicas). Observa-se que o texto da medida provisória no 495/2010 expressava como finalidade licitatória a "promoção do desenvolvimento nacional", mas quando a mesma foi convertida em Lei houve a mudança no texto passando a constar "promoção do desenvolvimento sustentável".

Em 2012, o Decreto $n^{\circ} 7.746$ veio regulamentar o art. $3^{\circ}$ da Lei $n^{\circ}$ 8.666/93 estabelecendo critérios, práticas e diretrizes para a promoção do desenvolvimento nacional sustentável nas contratações realizadas pela administração pública federal, além de instituir a Comissão Interministerial de Sustentabilidade na Administração Pública - CISAP ${ }^{26}$.

24 Foram eles: Paulo Bernardo Silva, Guido Mantega, Fernando Haddad e Sergio Machado Rezende.

25 Conforme sua exposição de motivos, tal Medida Provisória deveria ser adotada a fim de orientar o poder de compra do Estado para: promover o desenvolvimento econômico e para fortalecer cadeias produtivas de bens e serviços domésticos, incentivando assim, à pesquisa, à inovação e a tecnologia. Para tanto, utilizou-se de forma comparada tal política adotada nos Estados Unidos (Buy American Act de 1933 e American Recovery and Reinvestment Act de 2009), China (Lei n 68/2002), Colômbia (Lei n 816/2003) e Argentina (Lei $\left.n^{\circ} 25.551 / 2001\right)$.

26 A CISAP dentre suas funções deve propor à Secretaria de Logística e Tecnologia da Informação regras para a elaboração dos Planos de Gestão de Logística Sustentável PLS, o que foi feito via Instrução Normativa no 10/2012. Tais planos devem ser elaborados pelo órgão ou entidade e em sua elaboração, podem ser observados os programas já existentes. A Secretaria de Logística e Tecnologia da Informação determinou através da Instrução Normativa $n^{\circ}$ 10/2012 prazo para publicação dos PLS, e embora este prazo tenha sido prorrogado através da Portaria no 12/2013 do 
Comparando os dois instrumentos que abordam sobre o tema: (1) IN nº 01/2010 SLTI-MPOG e (2) Decreto $\mathrm{n}^{\circ} 7.746 / 12$, constatam-se diferenças em relação ao âmbito de abrangência, em relação ao que se entende por sustentabilidade e em relação a obrigação de fazer e semelhanças em relação a competitividade do certame.

Com relação a primeira diferença, a IN no $01 / 2010$ SLTI-MPOG refere que as especificações de sustentabilidade devem ocorrer por parte dos órgãos e entidades da administração pública federal direta, autárquica e fundacional deverão conter critérios de sustentabilidade ambiental, considerando os processos de extração ou fabricação, utilização e descarte dos produtos e matérias-primas. Neste ponto, o Decreto $\mathrm{n}^{\circ} 7.746 / 12$ aplica-se a administração pública federal direta, autárquica e fundacional e as empresas estatais dependentes, sendo, portanto, mais amplo.

Com relação a segunda, a IN nº 01/2010 SLTI-MPOG as especificações devem conter critérios de sustentabilidade ambiental, considerando os processos de extração ou fabricação, utilização e descarte dos produtos e matérias-primas, ou seja, o instrumento convocatório deverá formular as exigências de natureza ambiental. Nas licitações que utilizem como critério de julgamento o tipo melhor técnica ou técnica e preço, deverão ser estabelecidos no edital critérios objetivos de sustentabilidade ambiental para a avaliação e classificação das propostas. Já, o Decreto no 7.746/12 como já visto, as diretrizes de sustentabilidade abordam as três vertentes da mesma: econômico, ambiental e social, e não apenas a ambiental como a IN fez.

Com relação a terceira diferença, a IN no 01/2010 SLTI-MPOG deixa claro que as especificações para a aquisição de bens, contratação de serviços e obras deverão conter critérios de sustentabilidade ambiental. Esta clareza não está explícita no Decreto n $7.746 / 12$ que ora diz que os critérios e práticas de sustentabilidade de que trata $\mathrm{o}$ art. $2^{\mathrm{o}}$ serão veiculados como especificação técnica do objeto ou como obrigação da contratada, e ora diz que os órgãos poderão exigir no instrumento convocatório critérios de sustentabilidade. Ora diz que as especifica-

mesmo órgão, poucas entidades já o fizeram. Confira a lista disponível no link: http://189.9.150.57/publicacoescps, do MPOG. Após a elaboração dos PSL por todos os órgãos da Administração Pública Direta e Indireta (o que ainda não foi feito), os planos devem ser implantados e os resultados obtidos devem ser divulgados. Cabe em um estudo futuro analisar se os PSL foram efetivos. ções e demais exigências do projeto básico ou executivo para contratação de obras e serviços de engenharia devem ser elaboradas, nos termos do art. 12 da Lei n8.666/93, de modo a proporcionar a economia da manutenção e operacionalização da edificação e a redução do consumo de energia e água, por meio de tecnologias, práticas e materiais que reduzam o impacto ambiental. Ora diz que o instrumento convocatório poderá prever que o contratado adote práticas de sustentabilidade na execução dos serviços contratados e critérios de sustentabilidade no fornecimento dos bens.

Em relação a tais diferenças na realização de tais licitações ditas sustentáveis ${ }^{27}$, buscou-se respostas junto ao fórum colaborativo do site do MPOG, no link CPSUSTENTÁVEIS ${ }^{28}$. A resposta foi de que não há inconsistência em relação aos instrumentos no que tange a obrigatoriedade e sim, apenas em relação ao âmbito da abrangência, sendo o Decreto mais amplo.

Buscou-se também, através de e-mail enviado a Coordenadora de Compras do MPOG entender a questão da obrigatoriedade. A resposta dada foi de que:

Do Decreto 7.746/2012 e da Instrução Normativa $n^{\circ} 01 / 2010$ - SLTI, depreende-se a inteligência de que a utilização dos critérios de sustentabilidade deverá ocorrer quando possível, ressaltando-se, como condição sine qua non, a manutenção da maior competitividade possível. Ademais, é de suma importância ressaltar que somente a Lei específica pode criar novos critérios de habilitação/participação em procedimentos de aquisição de bens ou contratação de serviços por parte da Administração" (grifo do autor).

Realmente, a questão em preservar a competitividade é preocupação expressa nos dois documentos analisados. Para o cumprimento da IN no 01/2010 SLTI-MPOG o instrumento convocatório deverá formular as exigências de natureza ambiental de forma a não frustrar a competitividade. Da mesma forma, o Decreto $\mathrm{n}^{\circ}$ 7.746/12 diz que a adoção de critérios e práticas de sustentabilidade deverá ser justificada nos autos e preservar o caráter competitivo do certame. Talvez o equilíbrio em exigir critérios de sustentabilidade e a preservação do certame precise ser melhor trabalhado.

Agora não parece plausível a alegação de que o poder

27 Também chamadas de compras públicas sustentáveis", "compra ambientalmente amigável" ou "licitação positiva", "ecoaquisições", dentre outros.

28 BRASIL. Ministério do Planejamento. [Home Page]. Disponível em: <http://cpsustentaveis.planejamento.gov.br/ forum/discussions $>$. Acesso em: 12 fev. 2015. 
discricionário se sobreponha ao poder vinculado no caso em tela. Uma porque não há ação direta de inconstitucionalidade em relação ao Decreto nº 7.746/12 e duas, porque não teria qualquer sentido uma mudança legal que ampliasse o rol de órgãos, mas reduzisse a obrigação já imposta anteriormente. Desta forma, entende-se que a mudança ocorrida tentou unificar as tentativas de licitações sustentáveis obrigando a inserção de critérios de sustentabilidade para, no mínimo, a Administração Pública Federal.

A Administração Pública Federal ao adquirir bens ou contratar serviços e obras deve, portanto, levar em consideração critérios e práticas de sustentabilidade definidos de forma objetiva no instrumento convocatório.

No ano de 2010, o Tribunal de Contas da União TCU realizou uma Auditoria Operacional ${ }^{29}$ sobre ações implementadas pela Administração Pública Federal para promoção do uso racional e sustentável de recursos naturais, em especial, o consumo de energia elétrica, água e papel. A auditoria tinha como finalidade dentre outras, analisar a atuação do nível central do governo federal na busca da sustentabilidade quanto. Verificou-se a ausência de direcionamento claro do governo federal sobre a demanda das ações de sustentabilidade e de uso racional de recursos naturais pelos gestores públicos e, ao segundo, conclui-se que não há sistematização no gerenciamento das ações de sustentabilidade, além do baixo nível de institucionalização dessas ações. Isso sem falar do grande potencial de uso sustentável de recursos naturais na esfera federal, que não tem sido aproveitado ${ }^{30}$.

Constatou-se ainda que $73 \%$ dos órgãos pesquisados não realizam licitações sustentáveis, ou seja, quase 3/4 dos órgãos entrevistados declaram não seguirem a Instrução Normativa SLTI/MP no $1 / 10$.

No Acórdão resultado da auditoria, o TCU fez

29 Este procedimento abrangeu 71 órgãos e entidades e ocorreu via processo $017.517 / 2010-9$ que teve como resultado o Acórdão no 1.752/2011 - Plenário, onde foi Relator o Ministro-substituto André Luis de Carvalho. Insta observar que tal auditoria ocorreu no ano de 2010, mesmo ano da edição da Instrução Normativa SLTI/MP n ${ }^{\circ}$ 1/10 (em janeiro) e da Medida Provisória no 495/2010 (de julho) convertida na Lei $\mathrm{n}^{\circ}$ 12.349/2010 (em dezembro).

30 Segundo o Acordão do TCU (2011, p.44, \$287), o Ministério de Minas e Energia identificou um potencial de economia anual da ordem de $20 \%$ em energia elétrica, o que representaria um valor de R\$ 240 milhões no ano de 2009 e de $22 \%$ em relação à água, que representaria $\mathrm{R} \$ 67,5$ milhões por ano, ou seja, somente com energia elétrica e água poderia haver uma economia anual superior a $\mathrm{R} \$ 300 \mathrm{mi}-$ lhões por ano. várias recomendações ${ }^{31}$ e em 2013 resolveu monitorar o cumprimento deste Acórdão ${ }^{32}$. Como resultado, observou-se que ainda não é possível concluir que o resultado final esperado pelo Acórdão tenha sido alcançado. Dessa forma, determinou-se a realização de um monitoramento final neste ano.

\section{Pesquisa de campo}

\subsection{Metodologia de coleta de dados 4.1.1 Restrição da amostra}

Para medir a efetividade da obrigatoriedade da inserção de critérios sustentáveis na Administração Pública Federal é necessário coletar todos os instrumentos convocatórios, de todos os órgãos da Administração ou obter-se uma aproximação (proxy) disso.

Optou-se pela segunda forma. Assim, coletou-se os editais disponibilizados tanto no site do MPOG, quanto na Página de Transparência Pública.

Os primeiros referem-se a "editais e termos de referência sustentáveis" realizados entre 2010 a 2014 num total de 31 (trinta e um) e, os segundos foram aqueles efetuados pela Coordenação-Geral de Aquisições do MPOG durante o ano de 2014 num total de 26 (vinte e seis).

A amostra foi reduzida para 26 (vinte e seis) editais de referência, uma vez que, fixou-se o limite temporal de 2010 a 2014. Porém, o edital "Modelo TR" - sem número, da AGU de São Paulo, não foi possível ser analisado, uma vez que o documento foi erroneamente anexado, restando 25 (vinte e cinco) editais. Com relação aos editais da Coordenação, a amostra foi reduzida para 26 (vinte e seis) editais, uma vez que foram excluídas da análise, as licitações não finalizadas (ou seja, casos de "dispensa de licitação", "inexigibilidade de licitação", bem como situações "em andamento", "revogada", "anulada" e "suspensa"). Além disso, 04 (quatro) instrumentos convocatórios no site ( ${ }^{\circ}$ s $01,02,13$ e 21 ), não estavam disponíveis, restando 22 (vinte e dois) editais.

Assim, restaram 47 (quarenta e sete) instrumentos convocatórios $^{33}$. Destes, 25 (vinte e cinco) foram realiza-

Em especial o MMA, o MPOG e a Eletrobrás.

Via processo TC n 026.652/2013-7.

Alguns editais eram para Registro de Preços, mas foram analisados da mesma forma, já que o objeto é a identificação de critérios sustentáveis. Os editais estão disponíveis em: <http://cpsustentaveis.planejamento.gov.br/licitacoes-sustentaveis>. Acesso em: 10 fev. 2015. 
dos por vários órgãos ${ }^{34}$, ou seja, os editais "referenciais" e 22 (vinte e dois) realizados pela própria Coordenação-Geral de Aquisições do MPOG.

As escolhas de tempo e de espaço delimitados podem ser justificadas. Com relação ao tempo, a escolha deu-se pelo marco legislativo estabelecido, já que a IN $\mathrm{n}^{\circ} 01$ SLTI-MPOG é de janeiro de 2010, a Medida Provisória $\mathrm{n}^{\circ} 495$ é de julho de 2010, a Lei n 12.349/2010 é dezembro de 2010, o Decreto no 7.746 é de junho de 2012, a IN no 10 SLTI-MPOG é de novembro de 2012 e a Portaria no 12 é de maio de 2013. Desta forma, os editais analisados foram considerados desde 2010 (em face das mudanças normativas) até 2014 (prazo razoável para adaptação). Já, com relação ao espaço, optou-se por analisar os (1) editais de vários órgãos, uma vez os mesmos são considerados pelo MPOG como "editais de referência" em licitações sustentáveis e os (2) editais da Coordenação-Geral de Aquisições do MPOG, já que a primeira norma obrigando a Administração Pública Federal a inserir critérios de sustentabilidade originou-se deste Ministério.

\subsubsection{Levantamento de dados}

Uma vez selecionada a amostra, efetuou-se a leitura cuidadosa dos editais selecionados. Depois os editais foram catalogados com relação às suas tipologias. Após, identificou-se a forma como os critérios de sustentabilidade, quando existem, vem aparecendo nos instrumentos convocatórios.

\subsubsection{Resultados}

Após a primeira etapa foi possível classificar os editais em três tipos: editais para aquisição de produtos, editais para prestação de serviço e editais que exigem ambas, denominados editais mistos.

$\mathrm{Na}$ segunda etapa, foi possível observar que quando tais critérios podem ser identificados, estes são inseridos da seguinte forma:

a) pela exigência de alguma certificação ${ }^{35}$, por exemplo:

Os serviços devem ser realizados por empresa credenciada para certificação de sustentabilidade ambiental, de acordo com um dos seguintes processos, ou equivalente: AQUA do Brasil,

34 Estes disponíveis no link: <http://189.9.150.57/licitacoes-sustentaveis>, do MPOG. Acesso em: 10 fev. 2015.

35 Outras certificações são, por exemplo, etiqueta do Programa Nacional de Conservação de Energia Elétrica (PROCEL), Documento de Origem Florestal - DOF, ETIQUETA NACIONAL DE CONSERVAÇÃO DE ENERGIA - ENCE; EPA Energy Star, IEC 60950. processo Edifícios de Escritórios e Escolas; ou LEED NC, edifício administrativo ${ }^{36}$.

b) pela exigência de uma declaração de sustentabilidade ambiental, por exemplo;

DOS DOCUMENTOS NECESSÁRIOS PARA HABILITAÇÃO Para fins de habilitação ao certame, os interessados se obrigam a satisfazer os requisitos relativos a: DOCUMENTO PROBATÓRIO DE QUE POSSUI COMPROMISSO COM A SUSTENTABILIDADE AMBIENTAL, NOS TERMOS DA INSTRUÇÃO NORMATIVA N ${ }^{\circ} 1 / 2010$, CONFORME PREVISTO NO ITEM 9.5 DESTE EDITAL ${ }^{37}$.

c) na especificação do objeto ${ }^{38}$, por exemplo:

Os copos, talheres, pratos, utensílios variados, sacos multiuso, sacos de lixo produzidos a base de milho, com economia de $50 \%$ de energia no processo de produção, não depende de petróleo, tem redução de emissão de $\mathrm{CO} 2^{39}$.

Ressalta-se que em alguns editais além da Administração Pública exigir uma declaração, ela ainda especificava o objeto. Porém, para a análise foi apenas considerado um destes fatores, já que ambos demonstram que, ao menos, algum critério foi adotado.

Com relação aos editais "referenciais", os dados coletados podem ser visualizados relacionando o tipo do edital:

\begin{tabular}{|c|c|c|c|}
\hline \multirow{2}{*}{ tipos de edital } & aquisição de produtos & prestação de serviço & misto $^{1}$ \\
\cline { 2 - 4 } & 15 & 3 & 7 \\
\hline
\end{tabular}

E também levando em consideração a forma como o critério de sustentabilidade foi exigido:

\begin{tabular}{|c|c|c|c|c|}
\hline $\begin{array}{c}\text { critérios de } \\
\text { sustentabilidade } \\
\text { nos editais }\end{array}$ & $\begin{array}{c}\text { exigência de } \\
\text { certificação }\end{array}$ & $\begin{array}{c}\text { exigência de } \\
\text { declaração }\end{array}$ & $\begin{array}{c}\text { especificação do } \\
\text { objeto }\end{array}$ & $\begin{array}{c}\text { não foi possível } \\
\text { identificar }\end{array}$ \\
\hline $\begin{array}{c}\text { para aquisição } \\
\text { de bens }\end{array}$ & 5 & 2 & 6 & 2 \\
\hline $\begin{array}{c}\text { para prestação } \\
\text { de serviço }\end{array}$ & 3 & 0 & 0 & 0 \\
\hline Mistos & 1 & 2 & 2 & 2 \\
\hline
\end{tabular}

Já, com relação aos editais realizados pelo MPOG através da Coordenação-Geral de Aquisições ${ }^{40}$ e relacionados ao tipo do edital, os dados mostram que:

36 Conforme o Edital: Concorrência n 38.2012, BACEN.

37 Conforme o Edital: 00003/2010 (SRP) da Base de Fuzileiros Navais da Ilha das Flores.

38 Bens constituídos por material reciclado, atóxico ou biodegradável, coletor de resíduos, equipamentos com novas tecnologias.

39 De acordo com o Edital: Pregão no 22.2013, Marinha do Brasil.

40 CONTROLADORIA GERAL DA UNIÃO. Licitações. Disponível em: <http://www3.transparencia.gov.br/TransparenciaPublica/jsp/licitacoes/licitacaoTexto.jsf?consul$\mathrm{ta}=2 \&$ consulta $2=0 \&$ CodigoOrgao $=20404>$. Acesso em: 12 jan. 2015. 


\begin{tabular}{|c|c|c|c|}
\hline \multirow{2}{*}{ tipos de edital } & aquisição de produtos & prestação de serviço & misto $^{2}$ \\
\cline { 2 - 4 } & 8 & 9 & 5 \\
\hline
\end{tabular}

E, com relação forma como o critério de sustentabilidade foi exigido nestas licitações, os dados apontam que:

\begin{tabular}{|c|c|c|c|c|}
\hline $\begin{array}{c}\text { critérios de } \\
\text { sustentabilidade } \\
\text { nos editais }\end{array}$ & $\begin{array}{c}\text { exigência de } \\
\text { certificação }\end{array}$ & $\begin{array}{c}\text { exigência de } \\
\text { declaração }\end{array}$ & $\begin{array}{c}\text { especificação do } \\
\text { objeto }\end{array}$ & $\begin{array}{c}\text { não foi possível } \\
\text { identificar }\end{array}$ \\
\hline $\begin{array}{c}\text { para aquisição } \\
\text { de bens }\end{array}$ & 1 & 1 & 2 & 4 \\
\hline $\begin{array}{c}\text { para prestação } \\
\text { de serviço }\end{array}$ & 0 & 0 & 0 & 9 \\
\hline Mistos & 0 & 1 & 2 & 2 \\
\hline
\end{tabular}

De acordo com a relação das licitações sustentáveis realizadas no Comprasnet ${ }^{41}$ pode-se observar que das realizadas 2.292 (duas mil, duzentas e noventa e duas) licitações ocorridas, os bens ${ }^{42}$ mais consumidos foram: papel ${ }^{43}$, cartucho de tinta para impressoras, ar-condicionado, automóvel, impressora e computador.

Com os dados, pode-se perceber que a inserção de critérios de sustentabilidade pela Administração Pública Federal está ocorrendo de forma insuficiente. Isso por que: (1) os critérios sustentáveis quando exigidos, referem-se na sua maioria, apenas a vertente ambiental da sustentabilidade; (2) tornam-se mais nítidos nos editais para aquisição de bens os critérios de sustentabilidade, o que não ocorre nos editais para prestação de serviço; (3) sua exigência é parcial, já que em alguns editais como onde se exigia o fornecimento de vários produtos, os critérios sustentáveis não eram exigidos a todos os produtos.

Novamente, buscou-se respostas junto ao fórum colaborativo do site do MPOG, no link CPSUSTENTÁVEIS $^{44}$ a fim de saber se havia alguma exceção ou normativa interna que excluísse a necessidade da Coordenação-Geral de Aquisições de incluir tais critérios. A resposta foi de que:

${ }^{41}$ BRASIL. Ministério do Planejamento. [Home Page]. Disponível em: <http://cpsustentaveis.planejamento.gov.br/ licitacoes-sustentaveis $>$. Acesso em 10 fev. 2015. Estes editais são do tipo "aquisição de produtos" e não de "prestação de serviço".

42 Outros bens como lâmpadas, baterias, pilhas, cabos, plástico, lapiseira, almofada para carimbos e disjuntor aparecem nos pregões com menor frequência.

43 E seus derivados: caixas, envelopes, blocos, cartões.

44 BRASIL. Ministério do Planejamento. [Home Page]. Disponível em: <http://cpsustentaveis.planejamento.gov.br/ forum/discussions >. Acesso em: 12 fev. 2015.
O Ministério do Planejamento tem obrigatoriedade em incluir critérios de sustentabilidade nas especificações para a aquisição de bens, contratação de serviços e obras por ser um órgão da Administração Pública Federal direta. Contudo, por ainda haver discrepância na padronização das especificações dos editais, surge uma dificuldade na identificação dos critérios sustentáveis, assim, ainda não temos um banco de dados de editais sustentáveis do MP. Porém, estamos em fase de otimização dos processos através de ferramentas, como capacitações de servidores e este sítio, que contém recursos e orientações sobre compras sustentáveis.

Da mesma forma, a reposta do e-mail encaminhado a Coordenadora de Compras do MPOG trouxe como resposta que os critérios a serem utilizados ainda estão cativos ao âmbito da execução dos serviços. E o MPOG tem discricionariedade em exigir ou não tais critérios.

\section{0 fornecimento de bens e serviços sustentá- veis}

Antes da lei que exige a observância de critérios sustentáveis nas contratações públicas, poucas licitações sustentáveis eram realizadas (uma vez que ocorriam de forma facultativa e por alguns órgãos apenas, como já referidos) e poucos bens e serviços sustentáveis eram adquiridos. Ademais, não havia qualquer incentivo ao vendedor oferecer um produto sustentável, já que estes possuem um preço, em curto prazo, mais significativo, e isso poderia torná-lo perdedor do processo licitatório. Contudo, depois da lei, quando o comprador exige critérios sustentáveis, o vendedor é obrigado a oferecer produtos sustentáveis, caso queira vencer a licitação.

A exigência de critérios sustentáveis nas compras e contratações públicas gera também incentivos aos fornecedores a proverem mais opções sustentáveis desenvolvendo abordagens inovadoras e aumentando a competitividade da indústria nacional/local. De outra banda, percebe-se que muitas empresas ainda não se adequaram a estas novas exigências do mercado e podem ficar de fora da competição.

Quando a Administração Pública exige a inserção de critérios sustentáveis, algumas falhas do mercado são corrigidas: (1) não haverá externalidades negativas, as quais eram geradas a toda coletividade, com a produção de bens que danificavam o meio ambiente; (2) as licitantes são obrigadas a divulgarem uma informação privada (práticas de sustentabilidade desenvolvidas por estas), re- 
duzindo assim a assimetria de informações. Resta apenas que tais informações sejam críveis, ou seja, que possam ser verificadas, exigindo do poder público maior observância em relação a isto.

Cabe observar que a inserção de critérios de sustentabilidade deve ocorrer de forma clara para ambos os contratantes, a fim de evitar favorecimento entre os licitantes e assim, minimizar o problema do agente principal. Com isto, evitam-se também rescisões contratuais.

Exige-se também uma maior qualificação profissional na gestão ambiental pública para fornecer orientações claras a fim de selecionar fornecedores adequados e assim evitar o problema da seleção adversa. E também que esta qualificação ocorra na gestão ambiental privada, para que as empresas se tornem aptas a participar do processo licitatório.

Além disso, os contratos, uma vez firmados devem ser monitorados, a fim de evitar o problema do risco moral. Nesse sentido, a atuação do Tribunal de Contas da União torna-se imprescindível.

E, por fim, o catálogo de materiais e serviços feito pelo Sistema Integrado de Administração e Serviços Gerais - SIASG, o qual possibilita ao órgão administrativo a consulta dos bens sustentáveis já adquiridos pela Administração através sistema Comprasnet deve ser aprimorado, constantemente atualizado e amplamente divulgado.

\section{Conclusões}

O debate ambiental internacional exige dos Estados amigos do ambiente (e o Brasil se diz um) uma postura coerente entre seus discursos e práticas. Hoje, a sustentabilidade passou a ser: meta das empresas públicas e privadas; índice nas bolsas de valores; fundos de investimento de bancos; informada e monitorada pelos meios de comunicação e agora, critério para compras e contratações da Administração Pública Federal.

Não se busca aqui, questionar as diretrizes de sustentabilidade estabelecidas pelo Decreto $\mathrm{n}^{\circ} 7.746 / 12$ nem mesmo a forma pela qual o governo brasileiro está caracterizando determinado produto como um produto sustentável, questões que serão aprofundadas em outra ocasião.

Este trabalho teve apenas o objetivo de analisar a efetividade da obrigatoriedade da inserção de critérios de sustentabilidade nas compras públicas realizadas pela Administração Pública Federal.

Para tanto, utilizou-se uma análise dos editais de
2010 a 2014 considerados pelo MPOG como "referências" em termos de sustentabilidade, além dos editais realizados pela Coordenação Geral de Aquisições CGEAQ no ano de 2014.

As licitações sustentáveis que antes ocorriam de forma esparsa e voluntária, hoje se tornaram gerais e obrigatórias.

No passado, os processos licitatórios sustentáveis eram aqueles realizados em papel reciclado. No presente, a maioria de contratações ocorre por aquisição de material de expediente reciclado. No futuro, talvez se consiga compreender a dimensão da sustentabilidade e dar ela o seu devido valor.

A implementação das licitações sustentáveis no âmbito da Administração Pública Federal, embora traga uma melhora à imagem da autoridade pública, encontra ainda obstáculos a serem transpostos. E, tal fato fica ainda mais grave se analisado nas esferas estaduais e municipais, onde a escassez de recursos e controle são mais presentes.

A hipótese do presente estudo resta parcialmente comprovada no sentido de que a Administração Pública Federal nem sempre exige critérios sustentáveis nas compras realizadas, embora esta obrigação esteja prevista em lei, mas que quando assim faz, obriga que as licitantes ofereçam produtos sustentáveis.

Salienta-se que este estudo não tem qualquer pretensão de exaurir o tema proposto, mas cumpre seu papel, ao apresentar uma visão sistemática e argumentativa, oportunizando uma visão crítica acerca do tema.

\section{Referências}

AKAOUI, Fernando R. Vidal. Direito ambiental. In: NUNES JÚNIOR, Vidal Serrano. (Coord.). Manual de direitos difusos. São Paulo: Verbatiim, 2009. p. 9 - 83.

BAER, Werner. A economia brasileira. 2. ed. São Paulo: Nobel, 2002.

BRASIL. Constituição (1988). Constituição da República Federativa do Brasil. Disponível em: <http://www.planalto.gov.br/ccivil_03/constituicao/constituicaocompilado. htm>. Acesso em: 03 jan. 2015.

BRASIL. Decreto $n^{\circ} 2.783$ de 17 de Setembro de 1998. Dispõe sobre proibição de aquisição de produtos ou equipamentos que contenham ou façam uso das Substâncias que Destroem a Camada de Ozônio - SDO, pelos órgãos e pelas entidades da Administração Pública Federal direta, autárquica e fundacional, e dá outras providências. Disponível em: <http://www.planalto.gov.br/ccivil_03/ decreto/d2783.htm>. Acesso em: 20 jun. 2015. 
BRASIL. Decreto $n^{\circ}$ 7.746, de 5 de Junho de 2012. Regulamenta o art. $3^{\circ}$ da Lei $n^{\circ} 8.666$, de 21 de junho de 1993, para estabelecer critérios, práticas e diretrizes para a promoção do desenvolvimento nacional sustentável nas contratações realizadas pela administração pública federal, e institui a Comissão Interministerial de Sustentabilidade na Administração Pública - CISAP. Disponível em: <http://www.planalto.gov.br/CCIVIL_03/_Ato20112014/2012/Decreto/D7746.htm>. Acesso em: 20 jun. 2015.

BRASIL. Lei no 12.187, de 29 de Dezembro de 2009. Institui a Política Nacional sobre Mudança do Clima - PNMC e dá outras providências. Disponível em: <http://www. planalto.gov.br/ccivil_03/_Ato2007-2010/2009/Lei/ L12187.htm>. Acesso em: 20 jun. 2015.

BRASIL. Lei no 12.305 de 2 de Agosto de 2010. Institui a Política Nacional de Resíduos Sólidos; altera a Lei no 9.605, de 12 de fevereiro de 1998; e dá outras providências. Disponível em: <http://www.planalto.gov.br/ccivil_03/_Ato2007-2010/2010/Lei/L12305.htm>. Acesso em: 20 jun. 2015.

BRASIL. Lei no 12.349 de 15 de Dezembro de 2010. Conversão da Medida Provisória no 495 de 2010. Altera as Leis nos 8.666, de 21 de junho de 1993, 8.958, de 20 de dezembro de 1994, e 10.973, de 2 de dezembro de 2004; e revoga o $\$ 1^{\circ}$ do art. $2^{\circ}$ da Lei $n^{\circ} 11.273$, de 6 de fevereiro de 2006. Disponível em: <http://www.planalto.gov.br/ccivil_03/_Ato2007-2010/2010/Lei/L12349.htm>. Acesso em: 20 jun. 2015.

BRASIL. Lei $n^{\circ} 6.938$ de 31 de Agosto de 1981. Dispõe sobre a Política Nacional do Meio Ambiente, seus fins e mecanismos de formulação e aplicação, e dá outras providências. Disponível em: <http://www.planalto.gov.br/ ccivil_03/Leis/L6938.htm>. Acesso em: 20 jun. 2015.

BRASIL. Lei no 8.666 de 21 de Junho de 1993. Regulamenta o art. 37, inciso XXI, da Constituição Federal, institui normas para licitações e contratos da Administração Pública e dá outras providências. Disponível em: <http:// www.planalto.gov.br/ccivil_03/Leis/L8666cons.htm>. Acesso em: 20 jun. 2015.

BRASIL. Ministério do Meio Ambiente. [Home Page]. Disponível em: <http://www.mma.gov.br>. Acesso em: 06 out. 2012.

BRASIL. Ministério do Planejamento. [Home Page]. Disponível em: <http://www.planejamento.gov.br>. Acesso em: 10 jan. 2015.

BRASIL. Tribunal de Contas da União. [Home Page]. Disponível em: <http://portal2.tcu.gov.br/portal/page/ portal/TCU/Rio20/fichas/ptb_06_meio_ambiente.pdf $>$. Acesso em: 11 jan. 2015.
CONFERÊNCIA DAS NAÇÕES UNIDAS SOBRE O MEIO AMBIENTE E DESENVOLVIMENTO. Agenda 21. Rio de Janeiro: Ministério do Meio Ambiente, 1992. Disponível em: <http://ambientes,ambientebrasil.com. br/gestao/artigos/conerencia_das_nacoes_unidas_sobre_meio_ambiente_e_desenvolvimento_-_eco-92. html>. Acesso em: 26 out. 2012.

CONTROLADORIA GERAL DA UNIÃO. Licitações. Disponível em: <http://www3.transparencia.gov.br/ TransparenciaPublica/jsp/licitacoes/licitacaoTexto.jsf?consulta $=2 \&$ consulta $2=0 \&$ CodigoOrgao $=20404>$. Aces so em: 12 jan. 2015.

CROCKER, Keith J.; MASTEN, Scott E. Regulation and administered contracts revisited: lessons from transaction-cost economics for public utility regulation. Journal of Regulatory Economics. Dordrecht: Kluwer Academic Publishers, 1996, v. 9, p. 5-39. Disponível em: <http://deepblue.lib.umich.edu/bitstream/handle/2027.42/47841/11149_2004_Article_BF00134817. pdf ? sequence $=1$ \&isAllowed $=y>$. Acesso em: 02 fev. 2015 .

CÚPULA MUNDIAL SOBRE DESENVOLVIMENTO SUSTENTÁVEL. Declaração de Joanesburgo. Disponível em: <http://www.apambiente.pt/_zdata/Politicas/DesenvolvimentoSustentavel/2002_Declaracao_Joanesburgo. pdf $>$. Acesso em: 15 dez. 2014.

DEKEL, Omer. The legal theory of competitive bidding for government contracts. Public Contract Law Journal, v. 37, n. 2, p. 237-268, 2008. Disponível em: <http://www. jstor.org/discover/10.2307/25755452? sid=21105412419 281 \&uid $=60$ \&uid $=2134$ \&uid $=3737664 \&$ uid $=2 \&$ uid $=2$ 484585797 \&uid $=2484585807$ \&uid $=3 \&$ uid $=70>$. Acesso em: 10 dez. 2014.

FIORILlO, Celso Pacheco. Curso de direito ambiental brasileiro. 14. ed. São Paulo: Saraiva, 2013.

MACHADO, Paulo Affonso Leme. Direito ambiental brasileiro. 14. ed. São Paulo: Malheiros, 2006.

MEIRELLES, Hely Lopes. Direito administrativo brasileiro. 35. ed. São Paulo: Malheiros, 2009.

MELlO, Celso Antônio Bandeira de. Curso de direito administrativo. 29. ed. São Paulo: Malheiros, 2012.

RELATÓRIO BRUNDTLAND. Nosso futuro comum. Disponível em: <http://www.un.org/documents/ga/ res/42/ares42-187.htm>. Acesso em: 25 out. 2012.

ROSSETTI, José Paschoal. Introdução à economia. 18. ed. São Paulo: Atlas, 2000.

SACHS, Ignacy. Desenvolvimento: includente, sustentável, sustentado. Rio de Janeiro: Garamond, 2004. 
SECRETARIA DE LOGÍSTICA E TECNOLOGIA DA INFORMAÇÃO DO MINISTÉRIO DO PLANEJAMEN-

TO, ORÇAMENTO E GESTÃO. Instrução normativa $n^{\circ}$ 01 de 19 de Janeiro de 2010. Dispõe sobre os critérios de sustentabilidade ambiental na aquisição de bens, contratação de serviços ou obras pela Administração Pública Federal direta, autárquica e fundacional e dá outras providências. Brasília: MPOG, 2010.

\section{(Footnotes)}

1 Entendido aqui como todo o edital que além da aquisição de produto, exigiam a prestação de um serviço.

2 Entendido aqui como todo o edital que além da aquisição de produto, exigiam a prestação de um serviço. 